\title{
SISTEM PENDUKUNG KEPUTUSAN BIDANG MINAT MENGGUNAKAN METODE SIMPLE ADDITIVE WEIGHTING
}

\author{
Desi Indyastuti ${ }^{1}$, Joseph Dedy Irawan ${ }^{2}$, Renaldi Primaswara Prasetya ${ }^{3}$ \\ Program Studi Teknik Informatika S1, Fakultas Teknologi Industri \\ Institut Teknologi Nasional Malang, Jalan Raya Karanglo km 2 Malang, Indonesia \\ desii2929@gmail.com
}

\begin{abstract}
ABSTRAK
Lembaga Pendidikan Indonesia merupakan salah satu faktor yang penting dalam menentukan kemajuan suatu bangsa, karena dengan adanya pendidikan dapat mengembangkan berbagai potensi yang ada dalam diri seseorang. Pada Penelitian ini bertujuan untuk menentukan minat siswa yang ada pada SMA Sejahtera Prigen . Saat ini masih banyak siswa yang merasa bimbang dalam menentukan program studi di perguruan tinggi.

Dengan adanya penelitian ini bertujuan untuk membantu siswa dalam memilih program studi yang sesuai dengan minatnya. Dalam menentukan minat siswa maka diperlukannya tes minat bakat/Rothwell Miller Interest Blank(RMIB). Dengan dilakukannya tes minat bakat, ini dapat membantu menemukan minat dasar yang dimilki oleh siswa dan siswa dapat mengetahui bidang apa yang minatinya untuk menentukan program studi diperguruan tinggi.

Dari tes minat bakat tersebut jika hasil minat tersebut tidak sesuai dengan yang diharapkan akan berpengaruh terhadap masa depan siswa. Dari hasil test minat diSMA Sejahtera Prigen dan dihitung dengan menggunakan excel hasil perangkingan dengan metode simple additive weighting disimpulkan bahwa dari 23 siswa yang paling diminati dialtenatif Out/Outdoor.
\end{abstract}

Kata kunci : Sistem Pendukung Keputusan, Simple Additive Weighting, Minat Siswa

\section{PENDAHULUAN}

\subsection{Latar Belakang}

Lembaga Pendidikan Indonesia merupakan salah satu faktor yang penting dalam menentukan kemajuan suatu bangsa, karena dengan adanya pendidikan dapat mengembangkan berbagai potensi yang ada dalam diri seseorang. Dalam proses ini, siswa berhak mendapatkan pendidikan yang sesuai dengan minatnya. Saat ini pada SMA Sejahtera Prigen,masih banyak siswa yang bingung dan bimbang untuk nantinya menentukan program studi di perguruan tinggi yang sesuai dengan minatnya. Sistem Keputusan bidang minat siswa harus dipertimbangkan secara tepat agar hasil potensi siswa juga dapat dikembangkan secara maksimal.

Dari beberapa permasalahan yang sering muncul dalam penentuan minat siswa ke jenjang pendidikan perguruan tinggi salah satunya adalah dalam pengambilan suatu data, biasanya menghasilkan sebuah keputusan yang tidak sesuai dengan minatnya siswa. Sedangkan

pengambilan keputusan terdahap minat siswa sangat berpengaruh pada masa depan siswa.

Untuk menyelesaikan permasalahan tersebut maka perlu adanya tes The Rothwell Miller Interest Blank (RMIB) untuk membantu menemukan minat dasar yang dimilki oleh siswa, dan dapat mengetahui bidang yang diminati untuk menentukan program studi diperguruan tinggi. Sistem pendukung keputusan ini dapat membantu proses pengambilan keputusan masalah sehingga keputusan tersebut dapat menghasilkan minat siswa. Metode yang digunakan adalah metode Simple Additive Weighting (SAW). Metode Simple Additive Weighting (SAW) merupakanmetode penjumlahan pembobotan dari mencari penjumlahan terbobot dari rating dari tiap altenatif pada seluruh kriteria. Hasil atau Skor total yang diperoleh untuk sebuah alternatif yaitu dengan menjumlahkan semua hasil perkalian antara rating yang dibandingkan pada lintas atribut dan bobot setiap atribut. Rating pada setiap atribut sebelumnya harus sudah melalui proses normalisasi.

\subsection{Rumusan Masalah}

Berdasarkan latar belakang diatas maka penulis dapat merumuskan suatu perumusan masalah sebagai berikut :

1. Bagaimana cara merancang dan mengimplementasikan aplikasi Sistem pendukung keputusan bidang minat berbasis website?

2. Bagaimana cara mengimplementasikan metode tersebut untuk menyelesaikan masalah bidang minat siswa dengan menggunakan dengan metode Simple Additive Weighting $(S A W)$ ?

\subsection{Tujuan}

Berdasarkan rumusan masalah diatas maka dihasilkan suatu tujuan sebagai berikut :

1. Mempermudah siswa-siswi untuk mengambil keputusan berdasarkan minat yang dimiliki.

2. Salah satu cara untuk menumbuhkan minat siswa agar tidak salah mengambil program studi di perguruan tinggi. 
3. Mengimplementasikan metode SAW untuk menentukan program studi di perguruan tinggi.

\subsection{Batasan Masalah}

Agar pembahasan dalam penelitian ini tidak meluas, maka penulis mengambil beberapa batasan masalah, yaitu sebagai berikut :

1. Metode yang di gunakan untuk menyelesaikannya dengan menggunakan metode SAW.

2. Aplikasi ini hanya berbasis website

3. Aplikasi ini dibuat dengan Sublime Text(Tetxt Editor,Html ,dan Php sebagai Bahasa pemrogamannya)

4. Untuk Penyimpanan database dengan menggunakan $M y S Q L$

5. Target Pengguna yaitu Siswa-Siswi Sma Sejahtera Prigen.

\section{TINJAUAN PUSTAKA}

\subsection{Penelitian Terdahulu}

Menurut Penelitian Roini Faazada Muhammad sistem pendukung keputusan ini dilakukan menggunakan metode MOORA, dan menghasilkan pengujian akurasi perhitungan pada sistem dengan menggunakan perhitungan manual yaitu mencapai 95\%.Sistem pendukung keputusan penerimaan santri baru ini menghasilkan proses suatu perangkingan pada penerimaan santri baru dan menghasilkan kelas diniyah. Pada pengujian user ini telah menghasilkan yaitu untuk sangat buruk $0 \%$, buruk $8,3 \%$, cukup $30,3 \%$, baik $52,3 \%$, dan sangat baik 20,4\%.[1]

Menurut Penelitian Pradana Farid Muhammad hasil pada pengujian dengan menggunakan metode Topsis, pada alternatif yang paling memungkinkan untuk mendapatkan beasiswa yaitu atas nama ahmad sebagai karena nilai preferensi paling besar yaitu $=$ 0,70156 , sebagai alternatif yang paling besar akan yang dipilih. Dari hasil perangkingan tersebut digunakan untuk menentukan besiswa, serta menampilkan daftar siswa yang cocok untuk mendapatkan beasiswa tersebut.[2]

Menurut Penelitian Ismanto Edi, dkk dengan dilakukannya menggunakan metode SAW menghasilkan penerimaan baru dari karyawan pengolahan kriteria yang dipilih, sehingga dapat dijadikan sebagai pendukung dan pertimbangan dalam suatu pengambilan keputusan untuk mendapatkan karyawan baru. Metode SAW ini sering dikenal metode yang menggunakan penjumlahan terbobot dengan mencari penjumlahan setiap bobot dari masing masing altenatif.[3]

Menurut Penelitian Irawan Dedy Joseph, dkk menghasilkan mode untuk pengiriman secara individu dan group yang sangat memudahkan operator untuk mengirim pesan. Sistem informasi akademik berbasis SMS Gateway ini dengan menggunakan bahasa pemrograman yaitu Delphi dan MySQL. Pada pengiriman SMS dapat berjalan dengan lancar dengan kecepatan pengiriman sms relative sangat cepat.[4]

Menurut Penilitian Yulianti Wita menghasilkan suatu prediksi berdasarkan kemiripan kasus (similarity). Dari hasil perhitungan ini dengan menunjukkan nilai tingkat kepercayaan yaitu $60 \%$ maka solusi yang direkomendasikan yaitu ciri-ciri minat-bakat berupa kuisoner, dan bidang minat-bakat. Ciri-ciri minat-bakat dibuat untuk mempunyai nilai 1 yaitu nilai bobot yang diberikan. Pada nilai similarity ini ialah yang berada antara 0 dan 1 . Pada nilai 0 menunjukkan bahwa source case tidak ada yang cocok dengan target case dan jika nilai 1 bahwa source case sama dengan target case tersebut.[5]

Menurut Penelitian Raura Zensy Miranda, dkk menghasilkan secara keseluruhan minat siswa pada bidang studi yang ada disekolah sekitar 52,35\% siswa. Hubungan minat bidang studi dengan pekerjaan, berdasarkan hasil analisa data dapat diketahui bahwa terdapat dua jawaban. Pertama terdapat hubungan yang positif dan dignifikan antara minat bidang studi dengan pekerjaan pada siswa SMK Negeri 2 Banda Aceh khususnya pada bidang studi Teknik Otomotif, Teknik Bangunan, Teknik Komputer Jaringan dan Teknik Listrik pada tingkat kepercayaan sebesar 99\% dengan tingkat hubungan yang rendah dan cukup. Kedua tidak terdapat hubungan yang positif dan signifikan pada bidang Teknik Elektronika dan Teknik Mesin.[6]

\subsection{Sistem Pendukung Keputusan}

Sistem Pendukung Keputusan merupakan suatu sistem yang berbasis komputer interaktif yang memudahkan para pengguna pengambil keputusan dalam menggunakan data dan model untuk memecahkan sutatu masalah yang tidak terstruktur. Sistem pendukung keputusan dibangun guna menjadi alat bantu pengambilan keputusan untuk tetapi tidak untuk menggantikan penilaian yang sudah ada. Keputusan-keputusan yang membutuhkan penilaian merupakan tujuan dari adanya sistem pendukung keputusan. Biasanya sistem pendukung keputusan disebut juga dengan sistem terkomputerisasi yang mendukung pengambilan keputusan pada suatu organisasi.

\subsection{Simple Additive Weighting (SAW)}

Simple Additive weighting adalah metode yang sering dikenal sebgai metode penjumlahan bobot. Konsep dasar pada metode SAW ini adalah dengan mencari jumlah bobot dari setiap rating dan kinerja pada setiap alternatif, pada semua atribut. Metode SAW sangat membutuhkan proses normalisasi matriks keputusan yang ke suatu skala yang dapat diperbandingkan dengan semua rating alternatif yang ada, ada beberapa langkah penyelesaian dalam menggunakannya adalah:

1. Menentukan alternatif, yaitu Ai. 
2. Menentukan kriteria yang akan dijadikan acuan dalam pengambilan keputusan, yaitu $\mathrm{Cj}$.

3. Memberikan nilai rating kecocokan setiap alternatif pada setiap kriteria.

4. Menentukan bobot preferensi atau tingkat kepentingan (W) setiap kriteria. $\mathrm{W}=$ [ $\mathrm{W} 1, \mathrm{~W} 2, \mathrm{~W} 3, \ldots, \mathrm{WJ}]$

5. Membuat tabel rating kecocokan dari setiap alternatif pada setiap kriteria.

6. Membuat matrik keputusan (X) yang dibentuk dari tabel rating kecocokan dari setiap alternatif pada setiap kriteria. Nilai X setiap alternatif (Ai) pada setiap kriteria $(\mathrm{Cj})$ yang sudah ditentukan, dimana, $\mathrm{i}=1,2, \ldots \mathrm{m}$ dan $\mathrm{j}=1,2, \ldots \mathrm{n}$.

$$
X=\left[\begin{array}{cccc}
x 11 & x 12 & \ldots & x 1 j \\
\cdot & & & \cdot \\
x i 1 & x i 2 & \ldots & x i j
\end{array}\right]
$$

7. Melakukan normalisasi matrik keputusan $r i j=\left\{\begin{array}{l}\frac{X i j}{\operatorname{Max} X i j} \\ \frac{M i n X i j}{X i j}\end{array}\right\} \rightarrow$ jikaj adalah attribute biaya (cost) dengan cara menghitung nilai rating kinerja kemudian diternomalisasi (rij) dari alternatif $\mathrm{Ai}$ pada kriteria $\mathrm{Cj}$.

Dimana :

Ri $\mathrm{j}=$ nilai rating kinerja ternormalisasi $\mathrm{Xi}=$ nilai atribut yang dimiliki dari setiap kriteria Max xij = nilai terbesar dari setiap kriteria $\mathrm{i}$

Min xij = nilai terkecil dari setiap kriteria $\mathrm{i}$ Benefit $=$ jika nilai terbesar adalah terbaik Cost $=$ jika nilai terkecil adalah terbaik Dimana rij adalah rating kinerja ternormalisasi dari alternatif $\mathrm{Ai}$ pada atribut $\mathrm{Cj} ; \mathrm{i}=1,2, \ldots, \mathrm{m}$ dan $\mathrm{j}=1,2, \ldots, \mathrm{n}$.

8. Hasil dari nilai rating kinerja ternomalisasi (rij) membentuk matrik ternormalisasi (R)

$$
R=\left[\begin{array}{cccc}
r 11 & r 12 & \ldots & r 1 j \\
. & & & \cdot \\
r i 1 & r i 2 & \ldots & r i j
\end{array}\right]
$$

9. Hasil akhir nilai preferensi (Vi) diperoleh dari penjumlahan dari perkalian elemen baris matrik ternormalisasi (R) dengan bobot preferensi (W) yang bersesuaian eleman kolom matrik (W).

$$
V i=\sum_{j=1}^{n} W j r i j
$$

Di mana :

$\mathrm{Vi}=$ rangking untuk setiap alternatif

$\mathrm{wj}=$ nilai bobot dari setiap kriteria

rij = nilairating kinerja ternormalisasi Nilai

$\mathrm{Vi}$ yang lebih besar mengindikasikan bahwa alternatif Ai lebih terpilih.

\subsection{MINAT}

Minat adalah suatu ketertarikan yang ada pada dalam diri seseorang,minat juga suatu bentuk objek yang berasal dari hati dan diri,minat bukan karena paksaan dari orang lain.

\section{Ciri-Ciri Minat}

Menurut Elizabet B. Hurlock, berikut ini adalah ciriciri minat pada anak, yaitu:

1. Minat tumbuh dengan perkembangan fisik dan mental.

2. Minat bergantung pada kesiapan belajar.

3. Minat bergantung pada kesempatan belajar.

4. Perkembangan minat mungkin terbatas

5. Minat dipengaruhi pengaruh budaya.

6. Minat berbobot emosional.

7. Minat itu egonsentris.

\subsection{Rothwell Miller Interest Blank (RMIB)}

Rothwell Miller Interest Blank Tes Minat Rothwell pertama kali menyusun sebuah alat tes psikologi pada tahun 1947. Awalnya alat tes ini hanya memiliki 9 jenis kategori. Lalu tahun 1985 alat tes ini diperluas menjadi 12 kategori oleh Miller. Sejak saat itu tes psikologi ini menjadi Tes Interest RothwellMiller, yang dikenal dengan tes RMIB (Rothwell Miller Interest Blank). Sampai saat ini test RMIB yang digunakan terdiri dari 12 kategori jenis pekerjaan. Tujuan dari $R M I B$ adalah untuk mengukur interest pada seseorang berdasarkan minat seseorang terhadap suatu pekerjaan. Kegunaan teori ini digunakan dalam bidang konseling karir, konseling pekerjaan, penjurusan siswa dan perencanaan bahan bacaan siswa. Tes ini memiliki 12 kategori pekerjaan yaitu Out Door, Mechanical, Computational, Scientific, Personal Contact, Aesthetic, Literary, Musical, Social Service, Clerical.

\section{METODE PENELITIAN}

\subsection{Struktur Menu .}

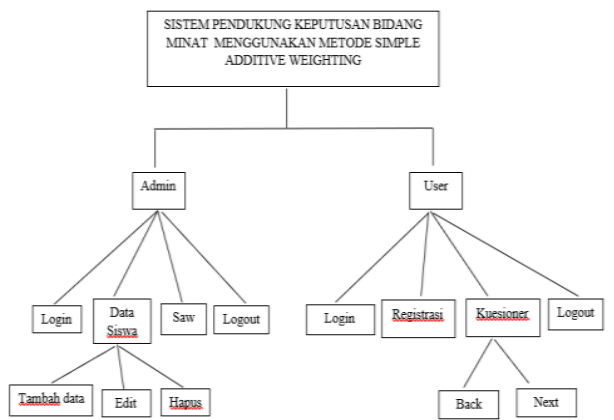

Gambar 1 Struktur Menu

Pada Gambar 1 ini menujukan beberapa menu yang ada pada website sistem pendukung keputusan bidang minat. Pada menu admin ada menu terdapat data siswa yang berisikan nama siswa,umur, dan juga jurusan,di menu data siswa admin bisa menggunakan menu tambah data,edit,dan juga hapus,kemudian di menu saw berisikan perhitungan hasil dari siswa yang telah menjawab kuesioner, Pada menu user terdapat menu login, registrasi,kuesioner yang berisikan pertanyaan-pertanyaan seputar minat dan bakat, dan di menu kuesioner user bisa menggunakan menu back dan juga next,kemudian logout. 


\subsection{Flowchart Metode SAW}

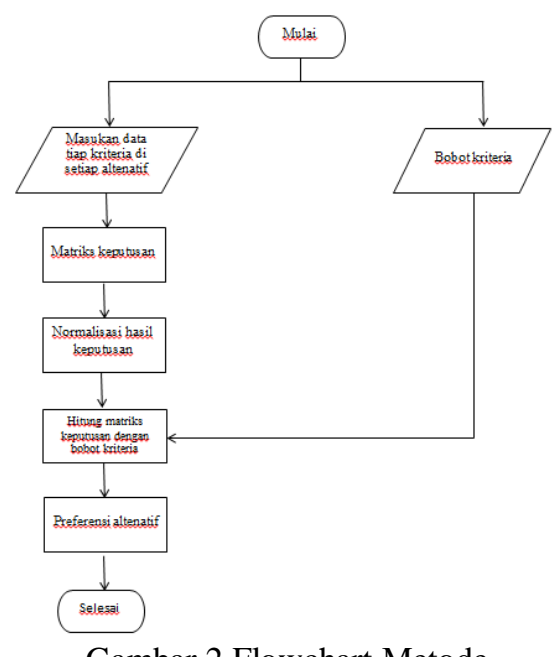

Gambar 2 Flowchart Metode

Pada gambar 2 ini menunjukan flowchart metode Simple Additive Weighting (SAW), dimulai dengan memasukan data tiap kriteria di setiap altenatif, kemudian langkah selanjutnya adalah menentukan Bobot kriteria seperti dapat dilihat pada Gambar 2 tahap selanjutnya adalah dengan menentukan Matriks keputusan,kemudian Normalisasi hasil keputusan,langkah selanjutnya adalah Hitung matriks keputusan dengan bobot kriteria, langkah terakhir adalah Preferensi altenatif yang sudah dihitung

\subsection{Pengujian Metode SAW}

Berikut ini adalah contoh langkah - langkah perhitungan metode SAW,dengan menggunakna excel data yang diperoleh dari Sma Sejahtera Prigen.

Langkah1.Menentukan altenatif,menentukan kriteria dan menentukan Bobot. Dapat dilihat pada Tabel 1. Merupakan tabel yang berisikan altenatif,kriteria ,dan bobot. Dari tabel tersebut terdapat 12 altenatif ,9 kriteria, dan juga 9 bobot. Dilihat dari data no 10-12 kriteria dan bobot tidak mempunyai kriteria dan bobot karena data dari test minat. Menghasillkan tersebut. Dari data tersebut akan diperoleh dan dihitung menggunakan metode Simple Additive Weighting.

Tabel 1 Menentukan altenatif,menentukan kriteria dan menentukan Bobot.

\begin{tabular}{|c|c|}
\hline Kriteria & Bobot \\
\hline A & 0,1 \\
\hline B & 0,1 \\
\hline C & 0,1 \\
\hline D & 0,2 \\
\hline E & 0,1 \\
\hline F & 0,1 \\
\hline G & 0,1 \\
\hline H & 0,1 \\
\hline I & 0,1 \\
\hline
\end{tabular}

\begin{tabular}{|c|c|}
\hline No & Altenatif \\
\hline 1 & Out \\
\hline 2 & Me \\
\hline 3 & Comp \\
\hline 4 & Sci \\
\hline 5 & Pers \\
\hline 6 & Aesth \\
\hline 7 & Lit \\
\hline 8 & Mus \\
\hline 9 & Socials \\
\hline 10 & Clear \\
\hline 11 & Prac \\
\hline 12 & Med \\
\hline
\end{tabular}

\begin{tabular}{|c|c|c|c|c|c|c|c|c|c|}
\hline & \multicolumn{10}{|c|}{ Kriteria } \\
\hline Altenatif & \multicolumn{10}{|c|}{} \\
\hline & A & B & C & D & E & F & G & H & I \\
\hline Out & 3 & 1 & 1 & 4 & 10 & 1 & 4 & 3 & 8 \\
\hline Me & 11 & 9 & 7 & 7 & 2 & 5 & 5 & 11 & 6 \\
\hline Comp & 7 & 5 & 5 & 9 & 5 & 2 & 6 & 10 & 1 \\
\hline Sci & 4 & 3 & 9 & 6 & 8 & 7 & 10 & 5 & 9 \\
\hline Pers & 5 & 11 & 3 & 10 & 7 & 10 & 1 & 2 & 7 \\
\hline Aesth & 1 & 2 & 6 & 11 & 6 & 8 & 12 & 12 & 2 \\
\hline Lit & 6 & 6 & 10 & 12 & 3 & 12 & 8 & 6 & 12 \\
\hline Mus & 10 & 8 & 8 & 1 & 9 & 6 & 7 & 7 & 10 \\
\hline Socials & 12 & 4 & 2 & 8 & 4 & 9 & 9 & 9 & 5 \\
\hline Clear & 9 & 10 & 11 & 3 & 11 & 4 & 11 & 1 & 11 \\
\hline Prac & 2 & 12 & 4 & 2 & 12 & 3 & 3 & 3 & 3 \\
\hline Med & 8 & 7 & 12 & 5 & 1 & 6 & 2 & 8 & 4 \\
\hline
\end{tabular}

Langkah 2.Melakukan Rating Kecocokan setiap Alternatif pada setiap Kriteria. Dapat dilihat pada tabel 2 ini merupakan 1 data siswa yang sudah mengikuti test minat, tabel memiliki data nilai yang disetiap kriteria dan altenatif , dari data tersebut diperoleh dari hasil test minat siswa tersebut, yang akan dihitung menggunakan metode Simple Additive Weighting.

Tabel 2 Memasukan Nilai setiap alternatif pada setiap kriteria.

Langkah 3. Penentuan matriks keputusan diperoleh dari rating kecocokan kinerja. Dilihat dari tabel 3 matriks, dari tabel tersebut berisikan hasil matriks normalisasi dari nilai altenatif dan langkah selanjutnya mengetahaui hasil akhir preferensi/peranghkinga.

Tabel 3 Menentukan matriks keputusan

\begin{tabular}{|l|l|l|l|l|l|l|l|l|}
\hline 0,333333 & 1 & 1 & 0,25 & 0,1 & 1 & 0,25 & 0,333333 & 0,125 \\
\hline 0,090909 & 0,111111 & 0,142857 & 0,142857 & 0,5 & 0,2 & 0,2 & 0,090909 & 0,166667 \\
\hline 0,142857 & 0,2 & 0,2 & 0,111111 & 0,2 & 0,5 & 0,166667 & 0,1 & 1 \\
\hline 0,25 & 0,333333 & 0,111111 & 0,166667 & 0,125 & 0,142857 & 0,1 & 0,2 & 0,111111 \\
\hline 0,2 & 0,090909 & 0,333333 & 0,1 & 0,142857 & 0,1 & 1 & 0,5 & 0,142857 \\
\hline 1 & 0,5 & 0,166667 & 0,090909 & 0,166667 & 0,125 & 0,083333 & 0,083333 & 0,5 \\
\hline 0,166667 & 0,166667 & 0,1 & 0,083333 & 0,333333 & 0,083333 & 0,125 & 0,166667 & 0,083333 \\
\hline
\end{tabular}




\begin{tabular}{|l|l|l|l|l|l|l|l|l|}
\hline 0,1 & 0,125 & 0,125 & 1 & 0,111111 & 0,166667 & 0,142857 & 0,142857 & 0,1 \\
\hline 0,083333 & 0,25 & 0,5 & 0,125 & 0,25 & 0,111111 & 0,111111 & 0,111111 & 0,2 \\
\hline 0,111111 & 0,1 & 0,090909 & 0,333333 & 0,090909 & 0,25 & 0,090909 & 1 & 0,090909 \\
\hline 0,5 & 0,083333 & 0,25 & 0,5 & 0,083333 & 0,333333 & 0,333333 & 0,333333 & 0,333333 \\
\hline 0,125 & 0,142857 & 0,083333 & 0,2 & 1 & 0,166667 & 0,5 & 0,125 & 0,25 \\
\hline
\end{tabular}

Langkah 4.Hasil dari matriks diperoleh dari penjumlahan dan perkalian baris pada matrik ternormalisasi (R) dengan bobot preferensi dengan maka hasil perangkingan yang dipilih nilai yang paling besar,sehingga nilai terbesar ada pada V1 dengan alteatif Out(Outdoor) sehingga kategori Out yang dipilih sebagai minat siswa.

$\left[\begin{array}{lll}0,449167 & 0,214531 & 0,282063 \\ 0,166508 & 0,275281 & 0,288258 \\ 0,164167 & 0,21246 & 0,199167 \\ 0,224899 & 0,283333 & 0,359286\end{array}\right]$

\section{HASIL DAN PEMBAHASAN}

\subsection{Hasil Minat Siswa}

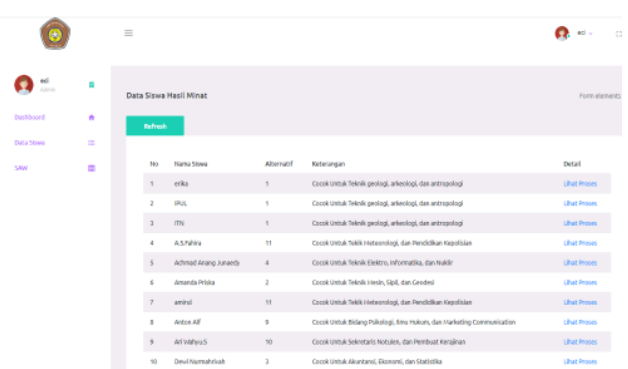

Gambar 3 Tampilan hasil minat siswa

Pada Gambar 3 adalah tampilan dari hasil perangkingan dengan menggunakan metode Simple Additive Weighting dan hasil dari 23 siswa di SMA Sejahtera Prige berminat masuk ke altenatif Out/Outdoor adalah kategori bakat dan minat yang mengarah pada kegiatan diluar ruangan. Dan dalam menu SAW ini user atau siswa tidak bisa mengakses yang hanya bisa mengakses hanya admin saja.

Tabel 4 Hasil Bidang Minat siswa

Pada Tabel 4 adalah tampilan dari hasil menggunakan metode Simple Additive Weighting, dengan 23 siswa ini berminat dialtenatif out(outdoor) sesuatu yang kegiataan diluar Ini hasil kesleuruhan minat siswa dengan minat yang berbeda beda.

\begin{tabular}{|l|l|c|lr|}
\hline No & Nama & Altenatif & \multicolumn{2}{|l|}{ Keterangan } \\
\hline 1 & $\begin{array}{l}\text { A.S } \\
\text { Fahira }\end{array}$ & 11 & \multicolumn{2}{l|}{$\begin{array}{l}\text { Cocok Untuk Teknik } \\
\text { kepolisian }\end{array}$} \\
\hline 2 & $\begin{array}{l}\text { Achma } \\
\text { d pendidikan }\end{array}$ & 4 & $\begin{array}{l}\text { Cocok Untuk Teknik } \\
\text { Elektro,Informatika dan } \\
\text { Anang } \\
\text { Junaed } \\
\text { yuklir. }\end{array}$ & \\
\hline 3 & $\begin{array}{l}\text { Amand } \\
\text { a Priska }\end{array}$ & 2 & $\begin{array}{l}\text { Cocok Untuk Teknik } \\
\text { Mesin,sipil,dan geodesi. }\end{array}$ \\
\hline
\end{tabular}

\begin{tabular}{|c|c|c|c|}
\hline 4 & Amirul & 11 & $\begin{array}{l}\text { Cocok Untuk Teknik } \\
\text { Meteorologi,dan } \\
\text { pendidikan kepolisian }\end{array}$ \\
\hline 5 & $\begin{array}{l}\text { Anton } \\
\text { Alf }\end{array}$ & 9 & $\begin{array}{l}\text { Cocok Untuk } \\
\text { Psikologi,ilmu hukum, dan } \\
\text { marketing communication }\end{array}$ \\
\hline 6 & $\begin{array}{l}\text { Ari } \\
\text { Wahyu. } \\
\text { S }\end{array}$ & 10 & $\begin{array}{lrr}\text { Cocok } & \text { Untuk } & \text { sekretaris } \\
\text { notulen } & \text {,dan } & \text { pembuat } \\
\text { kerajinan } & & \end{array}$ \\
\hline 7 & $\begin{array}{l}\text { Dewi } \\
\text { Nurma } \\
\text { hrivah }\end{array}$ & 3 & $\begin{array}{l}\text { Cocok } \\
\text { akuntansi,ekonomi,dan } \\
\text { statistika }\end{array}$ \\
\hline 8 & $\begin{array}{l}\text { Dimas } \\
\text { Ari }\end{array}$ & 4 & $\begin{array}{lr}\text { Cocok Untuk } & \text { Teknik } \\
\text { Elektro,Informatika } & \text { dan } \\
\text { nuklir. } & \end{array}$ \\
\hline 9 & $\begin{array}{l}\text { Dimas } \\
\text { Teguh }\end{array}$ & 9 & $\begin{array}{ll}\text { Cocok } & \text { Untuk } \\
\text { Psikologi,ilmu hukum, dan } \\
\text { marketing communication }\end{array}$ \\
\hline 10 & $\begin{array}{l}\text { Dzilatul } \\
. \mathrm{L}\end{array}$ & 6 & $\begin{array}{lr}\text { Cocok } & \text { Untuk } \\
\text { arsitek,fotografi, dan tata } \\
\text { rias kecantikan }\end{array}$ \\
\hline 11 & $\begin{array}{l}\text { Gigih } \\
\text { Irfansy } \\
\text { ah }\end{array}$ & 10 & $\begin{array}{lrr}\text { Cocok Untuk } & \text { sekretaris } \\
\text { notulen } & \text {,dan } & \text { pembuat } \\
\text { kerajinan } & & \\
\end{array}$ \\
\hline 12 & $\begin{array}{l}\text { M.Febr } \\
\text { iansah }\end{array}$ & 1 & $\begin{array}{l}\text { Cocok untuk teknik } \\
\text { geologi,arkeologi,dan } \\
\text { antropologi }\end{array}$ \\
\hline 13 & $\begin{array}{l}\text { M.Iqbal } \\
. F\end{array}$ & 2 & $\begin{array}{l}\text { Cocok Untuk Teknik } \\
\text { Mesin,sipil,dan geodesi. }\end{array}$ \\
\hline 14 & $\begin{array}{l}\text { M.Rez } \\
\text { ki.P }\end{array}$ & 10 & $\begin{array}{lrr}\text { Cocok Untuk } & \text { sekretaris } \\
\text { notulen } & \text {,dan } & \text { pembuat } \\
\text { kerajinan } & & \end{array}$ \\
\hline 15 & $\begin{array}{l}\text { Muham } \\
\text { mad } \\
\text { Noseh }\end{array}$ & 2 & $\begin{array}{l}\text { Cocok Untuk Teknik } \\
\text { Mesin,sipil,dan geodesi. }\end{array}$ \\
\hline 16 & $\begin{array}{l}\text { Nur } \\
\text { Rizky } \\
\text { Wahyu. } \\
\text { P }\end{array}$ & 1 & $\begin{array}{l}\text { Cocok untuk teknik } \\
\text { geologi,arkeologi,dan } \\
\text { antropologi }\end{array}$ \\
\hline 17 & $\begin{array}{l}\text { Popong } \\
\text {.RL }\end{array}$ & 10 & 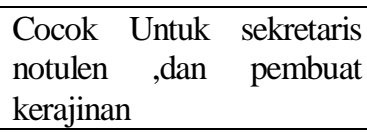 \\
\hline 18 & $\begin{array}{l}\text { Rafly } \\
\text { Wirgon } \\
\text { do }\end{array}$ & 5 & $\begin{array}{l}\text { Cocok } \\
\text { Komunikasi,Marketing,da } \\
\text { n teknik industri }\end{array}$ \\
\hline 19 & $\begin{array}{l}\text { Ragil.A } \\
\text {.F }\end{array}$ & 1 & $\begin{array}{l}\text { Cocok untuk teknik } \\
\text { geologi,arkeologi,dan } \\
\text { antropologi }\end{array}$ \\
\hline 20 & Reno & 4 & Cocok Untuk Teknik \\
\hline
\end{tabular}




\begin{tabular}{|l|l|c|l|}
\hline & $\begin{array}{l}\text { Azizul. } \\
\text { J }\end{array}$ & & $\begin{array}{l}\text { Elektro,Informatika dan } \\
\text { nuklir. }\end{array}$ \\
\hline 21 & $\begin{array}{l}\text { Revian } \\
\text { Afrizal. } \\
\text { A }\end{array}$ & 2 & $\begin{array}{l}\text { Cocok Untuk Teknik } \\
\text { Mesin,sipil,dan geodesi. }\end{array}$ \\
\hline 22 & $\begin{array}{l}\text { Rizky } \\
\text { Ayu }\end{array}$ & 1 & $\begin{array}{l}\text { Cocok untuk teknik } \\
\text { geologi,arkeologi,dan } \\
\text { antropologi }\end{array}$ \\
\hline 23 & $\begin{array}{l}\text { Yusron } \\
\text { Naufal. } \\
\text { A }\end{array}$ & 1 & $\begin{array}{l}\text { Cocok untuk teknik } \\
\text { geologi,arkeologi,dan } \\
\text { antropologi }\end{array}$ \\
\hline
\end{tabular}

\subsection{Pengujian Fungsional Sistem}

Pegujian adalah tahap uji coba terhadap pengujian fungsionalitas sistem, yang dilakukan untuk menjalankan semua fungsi disistem, apakah bekerja dengan dengan baik atau tidak. Pengujian dilalukan pada 2 browser pada perangkat dengan spesifikasi CPU yang digunakan adalah IntelCore i3-7020U, Procesor AMD 2.3 GHz.RAM 4 GB, dan penyimpanan Harddisk.

\begin{tabular}{|c|c|c|}
\hline Fungsi & $\begin{array}{l}\text { Google } \\
\text { Chrome }\end{array}$ & $\begin{array}{l}\text { Mozila } \\
\text { Firefox }\end{array}$ \\
\hline Login & $\sqrt{ }$ & $\sqrt{ }$ \\
\hline $\begin{array}{l}\text { Daftar admin } \\
\text { dan user }\end{array}$ & $\sqrt{ }$ & $\sqrt{ }$ \\
\hline $\begin{array}{l}\text { Menu Utama } \\
\text { pada admin } \\
\text { dan user }\end{array}$ & $\sqrt{ }$ & $\sqrt{ }$ \\
\hline $\begin{array}{l}\text { Tambah data } \\
\text { siswa }\end{array}$ & $\sqrt{ }$ & $\sqrt{ }$ \\
\hline $\begin{array}{l}\text { Edit dan } \\
\text { Hapus Data }\end{array}$ & $\sqrt{ }$ & $\sqrt{ }$ \\
\hline $\begin{array}{l}\text { Perhitungan } \\
\text { Menggunakan } \\
\text { Metode SAW }\end{array}$ & $\sqrt{ }$ & $\sqrt{ }$ \\
\hline $\begin{array}{l}\text { Input data } \\
\text { kuesioner }\end{array}$ & $\sqrt{ }$ & $\sqrt{ }$ \\
\hline $\begin{array}{l}\text { Hasil } \\
\text { kuesioner } \\
\text { minat siswa }\end{array}$ & $\sqrt{ }$ & $\sqrt{ }$ \\
\hline Logout & $\sqrt{ }$ & $\sqrt{ }$ \\
\hline
\end{tabular}

\subsection{PengujianUser}

Pengujian user merupakan respon dari responden yang diberikan. Pada penelitian ini, kuisioner diberikan kepada responden untuk menguji tampilan user.

\begin{tabular}{|l|l|l|l|l|}
\hline \multirow{2}{*}{ No } & \multicolumn{1}{|c|}{ Pertanyaan } & \multicolumn{3}{|c|}{ Penilaian } \\
\cline { 3 - 5 } & B & C & K \\
\hline 1 & $\begin{array}{l}\text { Apakah Tampilan awal } \\
\text { aplikasi sudah cukup } \\
\text { jelas? }\end{array}$ & $\sqrt{ }$ & & \\
\hline 2 & $\begin{array}{l}\text { Apakah ukuran dan } \\
\text { warna pada aplikasi ini } \\
\text { sudah cukup jelas? }\end{array}$ & $\sqrt{ }$ & & \\
\hline 3 & $\begin{array}{l}\text { Apakah tampilan form } \\
\text { Kuesioner mudah } \\
\text { dipahami? }\end{array}$ & $\sqrt{ }$ & & \\
\hline 4 & $\begin{array}{l}\text { Secara Keseluruhan } \\
\text { apakah pengguna } \\
\text { memuaskan pada } \\
\text { aplikasi ini? }\end{array}$ & $\sqrt{ }$ & & \\
\hline
\end{tabular}

\begin{tabular}{|l|l|l|l|l|}
\hline \multirow{2}{*}{ No } & \multicolumn{1}{|c|}{ Pertanyaan } & \multicolumn{3}{|c|}{ Penilaian } \\
\cline { 3 - 5 } & & B & C & K \\
\hline 5 & $\begin{array}{l}\text { Apakah menurut anda } \\
\text { aplikasi ini membantu } \\
\text { mempermudah anda } \\
\text { dalam menentukan } \\
\text { bidang minat? }\end{array}$ & $\sqrt{ }$ & & \\
\hline \multicolumn{2}{|l|}{ Total } & 5 & & \\
\hline
\end{tabular}

\section{KESIMPULAN DAN SARAN}

\subsection{Kesimpulan}

Adapun kesimpulan yang dapat ditulis dan di uraikan setelah melakukan sebuah perancangan sistem pendukung keputusan bidang minat menggunakan metode SAW ini adalah sebagai berikut.

1. Website sistem pendukung keputusan bidang minat siswa ini untuk mempermudah siswa-siswi dalam mengambil keputusan dalam penentuan program studi.

2. Dengan adanya sistem ini untuk menumbuhkan minat siswa-siswi agar tidak salah mengambil program studi.

3. Dalam mengimplementasikan dengan metode saw website sistem pendukung keputusan bidang minat ini ,dari siswa yang paling diminati ialah altenatif out(outdoor).

4. Pada pengujian fungsionalitas dilakukan menggunakan (MF) Mozila Firefox 72.0.1(64bit), dan Google Chrome 100\% dapat berjalan browser sesuai rancangan kebutuhan.

5. Dari tabel pengujian user mendapatkan kesimpulan bahwa 5 point menjawab baik terhadap konsistensi pengujian sistem

\subsection{Saran}

Adapun Saran Berdasarkan kesimpulan yang telah diuraikan diatas, maka diberikan saran sebagai berikut

1. Diharapkan sistem ini dapat bermanfaat dan dikembangkan oleh pihak Sekolah Menengah Atas(SMA).

2. Menambahkan fitur download dalam bentuk file excel untuk mempermudah pihak sekolah.

\section{DAFTAR PUSTAKA}

[1] Roini, Muhammad Faazada."Sistem Pendukung Keputusan Penerimaan Santri Baru Untuk Menentukan Kelas Diniyah Menggunakan Metode Moora(Multi Objective Optimization On The Basis Of Ratio Analysis)." JATI (Jurnal Mahasiswa Teknik Informatika) 3.1 (2019): 195-202.

[2] Pradana, Mukhammad Farid."Sistem Pendukung Keputusan Penentuan Pemberian Beasiswa Kepada Siswa Yang Berprestrasi Dan Yang Kurang Mampu Menggunakan 
Metode Topsis" JATI (Jurnal Mahasiswa

Teknik Informatika) 3.1 (2019): 211-218

[3] Ismanto, Edi, and Noverta Effendi. "Sistem Pendukung Keputusan Penerimaan Karyawan Dengan Metode Simple Additive Weighting (SAW)." SATIN-Sains dan Teknologi Informasi 3.1 (2017): 1-9.

[4] Irawan, Dedy Joseph, Emmalia Adriantantri, and Sonny Prasetio. "Sistem Informasi Akademik Berbasis SMS." Jurnal Teknik Informatika (2012) (2012): 47.

[5] Yulianti, Wita. "Aptitude Testing Berbasis Case-Based Reasoning dalam Sistem Pakar untuk Menentukan Minat Dan Bakat Siswa
Sekolah Dasar." J. Teknol. dan Sist. Inf. Univrab 1.2 (2016): 104-118.

[6] Raura, Miranda Zensy, Dahliana Abd, and M. Husen. "Hubungan Minat Bidang Studi Dengan Minat Pekerjaan Siswa Smk Negeri 2 Banda Aceh." JURNAL SULOH: Jurnal Bimbingan Konseling FKIP Unsyiah 3.1 (2018)

[7] Purwati, Neni. "Perancangan dan Implementasi Sistem Katalog Buku Secara Online Pada Perpustakaan Daerah Provinsi Lampung." Jurnal Informatika 11.1 (2014): 104-122 